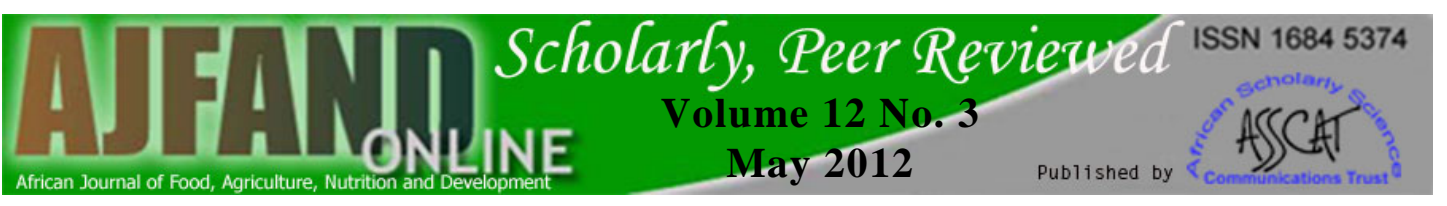

\title{
EFFECT OF CHEMICAL REFINING ON CITRULLUS COLOCYNTHIS AND PONGAMIA PINNATA SEED OIL
}

\section{Duhan $A^{* 1}$, Duhan $S^{2}$ and B Kumari ${ }^{3}$}

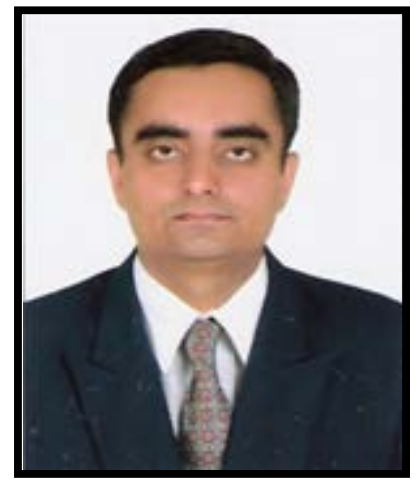

Anil Duhan

*Corresponding author email: a.duhan@rediffmail.com

${ }^{1}$ Department of Chemistry, CCS Haryana Agricultural University, Hisar 125004, India

${ }^{2}$ Department of Chemistry, Guru Jambheshwar University of Science and Technology, Hisar 125001, India

${ }^{3}$ Department of Entomology, CCS Haryana Agricultural University, Hisar 125004, India 


\section{ABSTRACT}

Bio-diesel production from conventional vegetable oils (soybean, sunflower, safflower, palm and rapeseed) has progressively stressed food uses, price, production and availability of these oils. Consequently, this has ignited the search for additional/ non-conventional, regional oil yielding raw materials to fulfill the increasing demand of oil for edible and bio-fuel production. Citrullus colocynthis and Pongamia pinnata (underutilized plants) oil was found to have good economical values. But crude oil obtained from natural resources contains a lot of impurities which should be removed before its use. Chemical refining involves degumming, alkali refining and bleaching are aimed to remove impurities like free fatty acids, phosphatides, metal ions, oxidation products and waxes. Oil from the both plant seeds was evaluated (both before and after refining) for different physico-chemical parameters like free fatty acids, iodine value, peroxide value, saponification value, unsaponifiable matter and fatty acid composition. Oil yield (30-35 \%) in both plants was found average. After refining, per cent reduction of free fatty acid value by (62.79 and 63.9), iodine value (25.59 and 27.37), saponification value (13.46 and 13.43), peroxide value (65.76 and 59.64) was observed in $C$. colocynthis and $P$. pinnata oil, which is helpful in increasing the oxidative stability and susceptibility towards trans-esterification. Unsaponifiable matter in $C$. colocynthis and $P$. pinnata was reduced by 54.78 and 49.78 per cent which is helpful in decreasing the amount of secondary metabolites and increasing the purity of oils. Analysis of $C$. colocynthis and $P$. pinnata oil shows that it was composed mainly of palmitic, stearic, oleic, linoleic and linolenic esters. After refining, saturated fatty acids were found reduced from 23.56 to 19.17 and 18.75 to 15.78 per cent and total unsaturated fatty acids were found to increase from 74.68 to 78.39 and 71.56 to 78.77 in both oils. It makes oil favorable for edible purposes as it can reduce plasma triglycerides.

Key words: Degumming, alkali refining, bleaching, oil 


\section{INTRODUCTION}

In view of the ever increasing demand of edible, non edible oils and their rather limited availability for industrial usage, it is of paramount importance to develop newer sources of fats and oils as raw material for these industries. This would facilitate the utilization of hitherto untapped non-traditional sources of vegetable oils. Crude oil, when extracted from vegetable, animal tissues and other sources are found to contain a number of impurities like free fatty acids, phosphatides, metal ions, waxes, oxidation products, colour bodies, which should be removed from the oil to make it suitable for human consumption and bio-fuel production. Removal of such kinds of impurities is done in a series of processes, which includes water degumming, alkali refining and bleaching of oil, which result in production of high quality oil having a good color, no taste or smell and remains fit for consumption, storage and transportation for long time [1,2]. These pre-treatment processes also solve the problem of oil deterioration and incomplete combustion as fuel. Further, it also increases the susceptibility of vegetable oils for trans-esterification during their conversion to biodiesel [3].

Citrullus colocynthis and Pongamia pinnata belong to family cucurbitaceae and leguminaceae, respectively. They occur wildly in different regions of India and are considered as underutilized plants [4]. C. colocynthis oil has good potential to be used for edible purposes and bio-diesel production [5]. However, $P$. pinnata oil is not of much importance from edible point of view because of presence of pongamol, which is toxic in nature but it can be a good biofuel alternate [6,7]. Keeping in view, six different physico-chemical properties like free fatty acids, iodine value, peroxide value, saponification value, unsaponifiable matter and fatty acid composition of $C$. colocynthis and $P$. pinnata oil were studied before and after the refining process. The objective of this study was to compare the experimental results in order to see the effect of chemical refining on oils, so as to provide useful information on the possible aspects of these under exploited food items for human consumption, food industry, bio-fuel and other technological uses.

\section{MATERIALS AND METHODS}

\section{Oil Extraction from Seeds}

Seeds of $C$. colocynthis and $P$. pinnata were procured from dryland research area of Chaudhary Charan Singh Haryana Agricultural University, Hisar and were sun dried before oil extraction. The dried seeds were blended and mixed thoroughly in a Lexus food mixer (Usha Lexus MG 2573, India). The powdered samples were then stored in an air-tight jar and kept in the refrigerator prior to analysis. Oil was extracted by solvent extraction method [8]. Defatted cake of C. colocynthis and P. pinnata were studied for crude protein. For that, nitrogen was estimated by the micro-kjeldahl method and the nitrogen percentage was converted to crude protein by multiplying with 6.25 as reported by Pearson [9]. For estimating oil yield the powdered seed sample was weighed in a thimble and placed in soxhlet apparatus. A dry pre-weighed solvent flask containing petroleum ether and condenser were attached and oil was extracted for $16 \mathrm{hrs}$. The thimble was removed and petroleum ether was retained. The 
excess of petroleum ether was than evaporated from the solvent flask on a hot water bath and dried the flask in a desiccator and weighed. Oil percent was calculated by subtracting the weight of empty flask from the weight of the flask containing the oil after the evaporation of the petroleum ether and dividing it by the weight of the sample taken in grams. Lecithin was estimated by solvent extraction method [8].

\section{Physico-chemical Parameters}

Free fatty acid: $50 \mathrm{ml}$ of denatured alcohol was added to $1 \mathrm{~g}$ of lipid sample in a 250 $\mathrm{ml}$ conical flask. The flasks were swirled and few drops of phenolphthalein were added and the contents were titrated against $0.1 \mathrm{~N}$ sodium hydroxide till a permanent light pink colour appeared, which persisted for at least 1 min [10]. The percentage of free fatty acids was calculated by using the following formula:

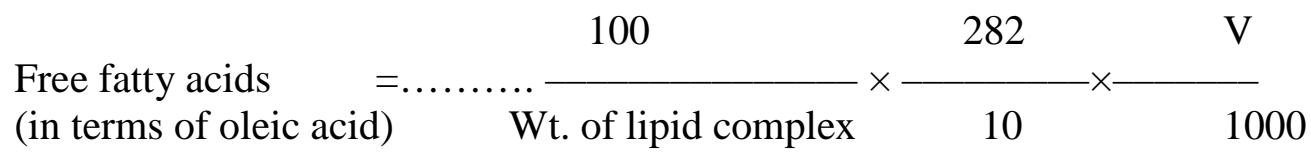

$\mathrm{V}=\quad$ Volume of $0.1 \mathrm{~N}$ sodium hydroxide used.

Iodine value: It was determined by titrating the chloroform and potassium iodine solution of $C$. colocynthis and P. pinnata with sodium thiosulphate solution using starch indicator [11].

Peroxide value: It was evaluated by dissolving the oil in a solvent mixture of acetic acid and carbon tetrachloride, warmed with potassium iodide and then titrated with sodium thiosulphate solution using starch indicator $[11,12]$.

Saponification value: It was determined by refluxing the alcoholic potassium hydroxide solution of the oil and then titrated with 0.5 M HCL using Phenolphthalein indicator as explained by Vogel [13].

Unsaponifiable matter: The unsaponifiables were estimated by dissolving the oil in alcoholic potassium hydroxide and refluxed. The homogeneous soda was then extracted with diethyl ether, the extract was filtered then oven dried to a constant weight [11].

Fatty acid spectrum: It was determined by method of Luddy et al. [12]. The oil was converted into methyl esters using a $\mathrm{KOH} / \mathrm{MeOH}$ method. The extracted fatty acid methyl esters (FAME) were dissolved in hexane for GC analyses.

\section{Fractionation of methyl esters by GC}

Analysis was performed using a Chemito 8610 HT Gas chromatograph equipped with FID and a BPX70, 0.25m $\mu$ fused silica column (SGE Pvt. Ltd., Ringwood, Victoria, Australia). The carrier gas was hydrogen and injection was operated in the split mode, the split ratio being approximately 50:1. Injector and detector temperatures were $270^{\circ} \mathrm{C}$ and $280^{\circ} \mathrm{C}$ respectively. The oven temperature was held at $70^{\circ} \mathrm{C}$ for $1 \mathrm{~min}$. and then programmed at $30^{\circ} \mathrm{C} / \mathrm{min}$ to $170^{\circ} \mathrm{C}$ followed by further programming at $30^{\circ} \mathrm{C} /$ 
min to $200^{\circ} \mathrm{C}$ and held at this temperature for 6 min. Data was captured and analyzed with, Chemito 5000 integrator (Tashniwal Instruments, India Ltd.).

\section{Degumming}

Crude oil was mixed with 2-3\% water, and it was agitated gently for 30-60 minutes at a temperature of $70^{\circ} \mathrm{C}$. Precautions were taken in order to prevent the introduction of air and subsequent oxidation of oil. Due to this, phosphatides and other impurities were settled down and were centrifuged (7000 rpm for 15 minutes) out from the degummed oil. This process resulted in recovery of lecithin and other materials that can settle out during shipment or storage of pure oil $[14,16]$.

\section{Alkali refining}

For alkali refining $0.1 \%$ caustic soda was added and thoroughly mixed to ensure saponification of free fatty acids, hydration of phosphatides, albuminous and mucilaginous matter and reactions with colored pigments. The mixture was then heated to $80^{\circ} \mathrm{C}$ and centrifuged (7000 rpm for 15 minutes) to separate out the caustic from refined oil. Next the refined oil was heated to $88^{\circ} \mathrm{C}$ mixed with $10-20 \%$ soft water and was again centrifuged to separate into heavy and light phases [15].

\section{Bleaching}

One percent of activated charcoal was added to the oil obtained after centrifugation. It was stirred for half an hour and heated to $100^{\circ} \mathrm{C}$, then filtered, cooled and subjected to GLC analysis. The identification of the peaks was achieved by retention times and by comparing them with authentic standards [16] analyzed under the same conditions [15].

\section{Statistical analysis}

The data were analyzed using (ANOVA) for the complete randomized design (CRD) where each observation was replicated thrice. To compare the treatments, critical difference $(\mathrm{P}=0.05)$ was calculated.

\section{RESULTS}

Oil, lecithin and protein yield in $C$. colocynthis and $P$. pinnata has been reported in Table 1. Percent oil yield in $C$. colocynthis and $P$. pinnata was observed to be 34.24 and $30.65 \%$ respectively. Crude protein in defatted cake of $C$. colocynthis and $P$. pinnata was found to be 27.62 and $19.18 \%$ in $P$. pinnata. Amount of lecithin in $C$. colocynthis and $P$. pinnata was found to be 1.39 and $1.63 \%$, respectively.

Free fatty acid: In C. colocynthis and $P$. pinnata oil, free fatty acid value (Table 2) before refining was found to be 0.86 and $0.62 \mathrm{mg} \mathrm{KOH} / \mathrm{g}$ oil, respectively. These values compared favorably with the results obtained by Bringi and Mabaleha et al. $[17,18]$. After refining, the free fatty acid value of $C$. colocynthis and $P$. pinnata reduced to 0.32 and $0.23 \mathrm{mg} \mathrm{KOH} / \mathrm{g}$ oil, thereby showing 62.79 and $63.90 \%$ reduction, respectively. 
Iodine value: In C. colocynthis and P. pinnata iodine value before refining was found to be 119.33 and $87.36 \mathrm{~g} / 100 \mathrm{~g}$ oil, respectively. These values compared favorably with the results obtained by Demirbas [3]. Per-cent reduction of 25.59 and 27.37 in iodine value was observed after refining in $C$. colocynthis and $P$. pinnata oil, respectively.

Peroxide value: Before refining process, Its value was found to be 2.95 and 1.66 $\mathrm{meq} / \mathrm{kg}$ oil in $C$. colocynthis and $P$. pinnata, respectively which get reduced (after refining) to 1.01 and $0.67 \mathrm{meq} / \mathrm{kg}$ oil, showing 65.76 and $59.64 \%$ reduction. Duhan et al.[19] also observed similar reduction trend in peroxide value after refining in Psophocarpus tetragonolobus.

Saponification value: Before refining, in C. colocynthis and $P$. pinnata oils its value was 190.38 and $178.80 \mathrm{mg} \mathrm{KOH} / \mathrm{g}$ oil respectively. The percent reduction in saponification value after refining was 13.46 and 13.43. Earlier Solomon et al. also observed nearly similar saponification values in unrefined C. Colocynthis oil [20].

Unsaponification matter: C. colocynthis and P. pinnata oils had very low unsaponification matter (1.57 and 2.29\%, respectively) before refining, which further reduced to 0.71 and $1.15 \%$ after refining, therefore, showing 54.78 and $49.78 \%$ reduction. Similar reduction pattern (after refining) in different physico-chemical properties of $J$. curcas and P. tetragonolobus oil was observed by Duhan et al. [19, 21].

Fatty Acid Spectrum: Palmitic acid, which is considered as the major saturated fatty acid, (Table: 3 ) was found to be 10.90 and $11.65 \%$ before refining which reduced to 8.56 and $9.42 \%$ after refining in $C$. colocynthis and $P$. pinnata oil, respectively. Nearly similar trend of reduction in stearic acid (another major saturated fatty acid) value was also observed. C. colocynthis have relatively high stearic acid value, both before and after refining (12.66 and 10.61\%). Oleic acid, which is considered as major unsaturated fatty acid get increased (after refining process) from 52.12 to $57.26 \%$ in $P$. pinnata oil. Amount of linolenic acid (before refining) was found to be $0.55 \%$ in $C$. colocynthis oil and $0.72 \%$ in $P$. pinnata oil which gets reduced (after refining) to 0.43 and $0.64 \%$ in seed oil from both plants. Total unsaturated fatty acid in C. colocynthis and P. pinnata get increased after refining from 74.68 and 71.56 to 78.39 and $78.77 \%$ and total saturated fatty acid get decreased from 23.56 and 18.75 to 19.17 and $15.78 \%$ respectively.

\section{DISCUSSION}

Oil yield percentage (34.24 and 30.65\%) in C. colocynthis and P. pinnata was found to be comparable with the percent oil yield of Groundnut oil (35-47\%), therefore $C$. colocynthis and $P$. pinnata can be used as a potential oil yielding crop [22]. It was observed that amount of crude protein in the defatted cake of $C$. colocynthis and $P$. pinnata was not high (27.62 and 19.18\%) but the cake can be used as a feed, manure and fertilizer. 
In most plants, seed oil contained phosphatides in the form of lecithin. A large part of these phosphatides in the crude oils can be hydrated and can be removed by water degumming [23]. In this study it is observed that 1.39 and $1.63 \%$ lecithin get removed by water degumming process from $C$. colocynthis and $P$. pinnata oil respectively. It was observed that once these phosphatides get removed in the form of lecithin, than no further appearance of gums or waxes in the oil take place and it result in the production of oil having good colour, no taste or smell and remains fit for storage and transportation for long time (2-3 years) [23]. It was also observed in pervious study that the phosphatides if present in the fuel oil did not combust completely in engine, and thus results in carbon deposits and thickening of lubrication [24]. This problem can therefore be solved by removing phosphatides by degumming as shown in the present study. The obtained by-product of this process (lecithin) has wide commercial applications. Industrially produced lecithin (mainly as by-product from petroleum refinery) can be used in food and beverages, medicines, cosmetics, tobacco, lubricants, gasket and cork products, urethan polymer, soap production [25, 26].

Free fatty acid is an indicator of quality, the freshness and the efficiency of the refining process. It has been reported that $<0.5 \%$ FFA content is required for successful trans-esterification to avoid soap formation [27]. Further it was also noticed in previous research that high acid value makes the fuel prone to polymerization and the fuel start acting as catalyst for hydrolysis [28]. This may be due to the reason that in crude oil, release of short chain fatty acids (free fatty acids) such as butyric, caproic and capric acid; cause particularly disagreeable odors and flavour whereas the long chain fatty acids $\left(\mathrm{C}_{12}\right.$ and above) produce candle like or alkaline $\mathrm{pH}$, soapy flavour [28]. This problem can be solved by removing extra fatty acids and alkali refining has been found very effective in doing so. In the present study, removal of about 62.79 and $63.90 \%$ free fatty acid from C. colocynthis and $P$. pinnata oil support the efficiency of this process. It was observed that high free fatty acid level of crude oil is mainly due to high activity of enzyme lipase, whereas in processed oils lipase activity was found minimal which result in decrease of free fatty acid content in such oils [22].

Decrease in iodine value after refining; represent the decrease in unsaturation of oil which is beneficial in the sense that the lower the unsaturation of oils and fats, the greater will be its oxidative stability [22]. After refining process, $P$. pinnata oil having iodine value $(63.45 \mathrm{~g} / 100 \mathrm{~g}$ oil) lower then C. colocynthis oil (88.79 g/100 g oil) should be more oxidative stable. McDonnell et al. noticed that low iodine value oil produce biodiesel with high cloud and pour point that have poor cold performance [24]. So P. pinnata oil having low iodine value after refining is a poor alternate for biodiesel production as compared with $C$. colocynthis.

Oxidation of lipids is a major cause of their deterioration, and hydroperoxide formed by the reaction between oxygen and the unsaturated fatty acids are the primary products of these reactions. Hydroperoxides have no flavour or odour but break down rapidly to form aldehydes, which have a strong, disagreeable flavour and odour. Refining of oils can result in considerable decrease of peroxide values of various oils; make them ideal for consumption and storage. In the present study peroxide value 
after refining in $C$. colocynthis oil get reduced by $65.76 \%$. Its low value make it superior than $P$. pinnata oil in which there was a reduction of about $59.64 \%$. Decrease in peroxide value after refining, increases its suitability for the long time storage because of having low level of oxidative and lipolytic activities. Saponification value is a measure of the alkali reactive groups in fats and oils and is useful in predicting the type of glycerides in a sample. $P$. pinnata oil having low saponification value (154.79 $\mathrm{mg} \mathrm{KOH} / \mathrm{g}$ oil), thus found better than C. colocynthis oil (164.75 mg KOH/g oil) because biodiesel derived from oil with high saponification value cause exhaust emissions during burning in the engine [29]. Unsaponifiables are the count of secondary metabolites present in the oil. Their presence in oil can deteriorate the purity of the oil. Removal of higher amount of unsaponifiables from $C$. colocynthis oil (54.78\%) as compared to $P$. pinnata oil $(49.78 \%)$ during refining increases the importance (from purity point of view) of $C$. colocynthis over the $P$. pinnata oil.

Fatty acid spectrum is highly valuable for prediction about the degree of saturation of oil. C. colocynthis have relatively high stearic acid value, both before and after refining (12.66 and 10.61\%) which is harmful because it can cause anthrosclerotic plaque. Oleic acid value in $P$. pinnata (52.12 before refining and $57.26 \%$, after refining) is comparable with rapeseed oil (59.62 to 60.66\%) which indicates its edible utility [30]. Higher levels of oleic acid are desirable to impart stability to oil during storage and deep fat frying [30]. Linolenic acid, which is considered to be a potential anti-nutritional compound [22] was found as 0.55 and $0.72 \%$ in C. colocynthis and $P$. pinnata oil. Its value gets reduced (after refining) to 0.43 and $0.64 \%$ in C. colocynthis and $P$. pinnata oil. In this respect $C$. colocynthis oil having low percentage of linolenic acid was found to be superior to $P$. pinnata oil. Total unsaturated fatty acid in $C$. colocynthis and $P$. pinnata oil were found to be increased after refining from 74.68 and 71.56 to 78.39 and $78.77 \%$, respectively. On the other hand, refining process led to decrease in total saturated fatty acid from 23.56 and 18.75 to 19.17 and $15.78 \%$ in oil from both plants. This small variation in fatty acid composition of both crude and refined oil had been noticed due to slight oxidation of linolenic acid during the process of refining [31]. It makes oil favorable for edible purpose as it can reduce plasma tri-glycrides and thus considered anti-thrombogenic too. The fatty acid profile of $C$. colocynthis and $P$. pinnata was found much similar to that of Jatropha oil which is considered as good quality bio-diesel producing plant [21].

\section{CONCLUSION}

It can be concluded from the results that $C$. colocynthis and $P$. pinnata seed oil have good nutritional profile and other physico-chemical properties, which were further improved after the refining process; therefore, it can be used as a potential oil seed resource for both edible and bio-fuel production. 


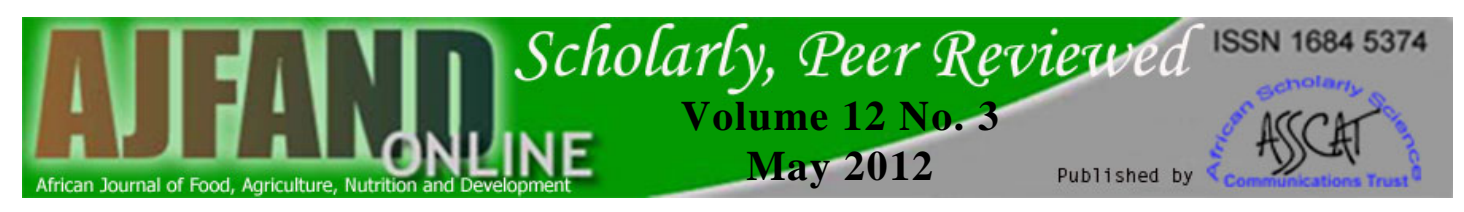

Table 1: Oil yield, protein in defatted cake and lecithin in oil of $C$. colocynthis and P.pinnata

\begin{tabular}{|c|c|c|c|}
\hline & Oil (\%) $\pm S D$ & $\begin{array}{c}\text { Lecithin (\%) in oil } \\
\pm S D\end{array}$ & $\begin{array}{c}\text { Protein (\%) in defatted cake } \\
\pm S D\end{array}$ \\
\hline C. colocynthis & $34.24 \pm 0.41$ & $1.39 \pm 0.17$ & $27.62 \pm 0.50$ \\
\hline P. pinnata & $30.65 \pm 0.28$ & $1.63 \pm 0.20$ & $19.18 \pm 0.32$ \\
\hline
\end{tabular}

No. of replicates $(\mathrm{R})=3$

Table 2: Effect of refining process on different physico-chemical properties of $C$ colocynthis and $P$. pinnata oil

\begin{tabular}{|c|c|c|c|c|c|c|c|c|}
\hline \multicolumn{5}{|c|}{ C. colocynthis } & \multicolumn{4}{|c|}{ P. pinnata } \\
\hline & $\begin{array}{l}\text { Before } \\
\text { refining }\end{array}$ & $\begin{array}{l}\text { After } \\
\text { refining }\end{array}$ & $\begin{array}{c}\text { Reduction } \\
\text { (\%) }\end{array}$ & $\begin{array}{c}\mathrm{CD} \text { at } \\
\mathrm{P}= \\
(0.05)\end{array}$ & $\begin{array}{l}\text { Before } \\
\text { refining }\end{array}$ & $\begin{array}{l}\text { After } \\
\text { refining }\end{array}$ & $\begin{array}{c}\text { Reduction } \\
\text { (\%) }\end{array}$ & $\begin{array}{c}\text { CD at } \\
P= \\
(0.05)\end{array}$ \\
\hline $\begin{array}{c}\text { Free fatty acid } \\
\text { (mg KOH/g } \\
\text { oil) } \\
\pm S D\end{array}$ & $0.86 \pm 0.02$ & $0.32 \pm 0.05$ & 62.79 & 0.05 & $0.62 \pm 0.01$ & $0.23 \pm 0.01$ & 63.90 & 0.037 \\
\hline $\begin{array}{c}\text { Iodine value } \\
\text { (g/100g oil) } \pm \\
S D \\
\end{array}$ & $119.33 \pm 0.60$ & $88.79 \pm 1.48$ & 25.59 & 4.06 & $87.36 \pm 0.61$ & $63.45 \pm 1.18$ & 27.37 & 3.104 \\
\hline $\begin{array}{l}\text { Peroxide value } \\
\text { (meq/kg } \\
\text { oil) } \pm S D\end{array}$ & $2.95 \pm 0.12$ & $1.01 \pm 0.04$ & 65.76 & 0.29 & $1.66 \pm 0.04$ & $0.67 \pm 0.04$ & 59.64 & 0.126 \\
\hline $\begin{array}{c}\text { Saponification } \\
\text { value } \\
\text { (mg KOH/g } \\
\text { oil) } \\
\pm S D\end{array}$ & $190.38 \pm 0.71$ & $164.75 \pm 0.84$ & 13.46 & 2.58 & $178.80 \pm 0.55$ & $154.79 \pm 1.50$ & 13.43 & 3.748 \\
\hline $\begin{array}{c}\text { Unsaponifiable } \\
\text { matter }(\%) \\
\pm S D\end{array}$ & $1.57 \pm 0.07$ & $0.71 \pm 0.02$ & 54.78 & 0.18 & $2.29 \pm 0.04$ & $1.15 \pm 0.02$ & 49.78 & 0.108 \\
\hline
\end{tabular}

No. of replicates $(\mathrm{R})=3$ 


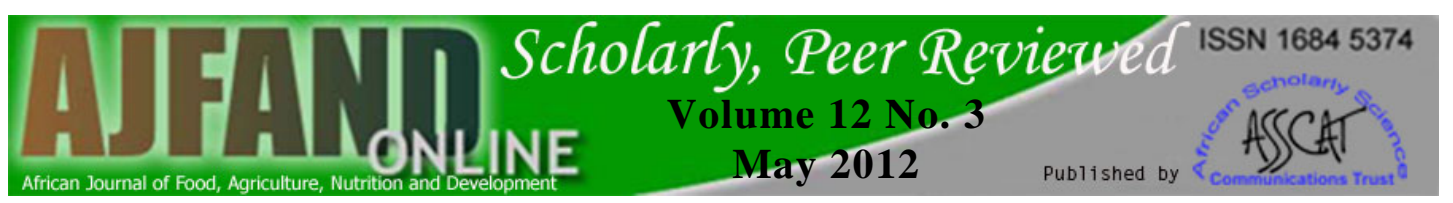

Table 3: Fatty acid composition before and after oil refining in $C$. colocynthis and P. pinnata oil

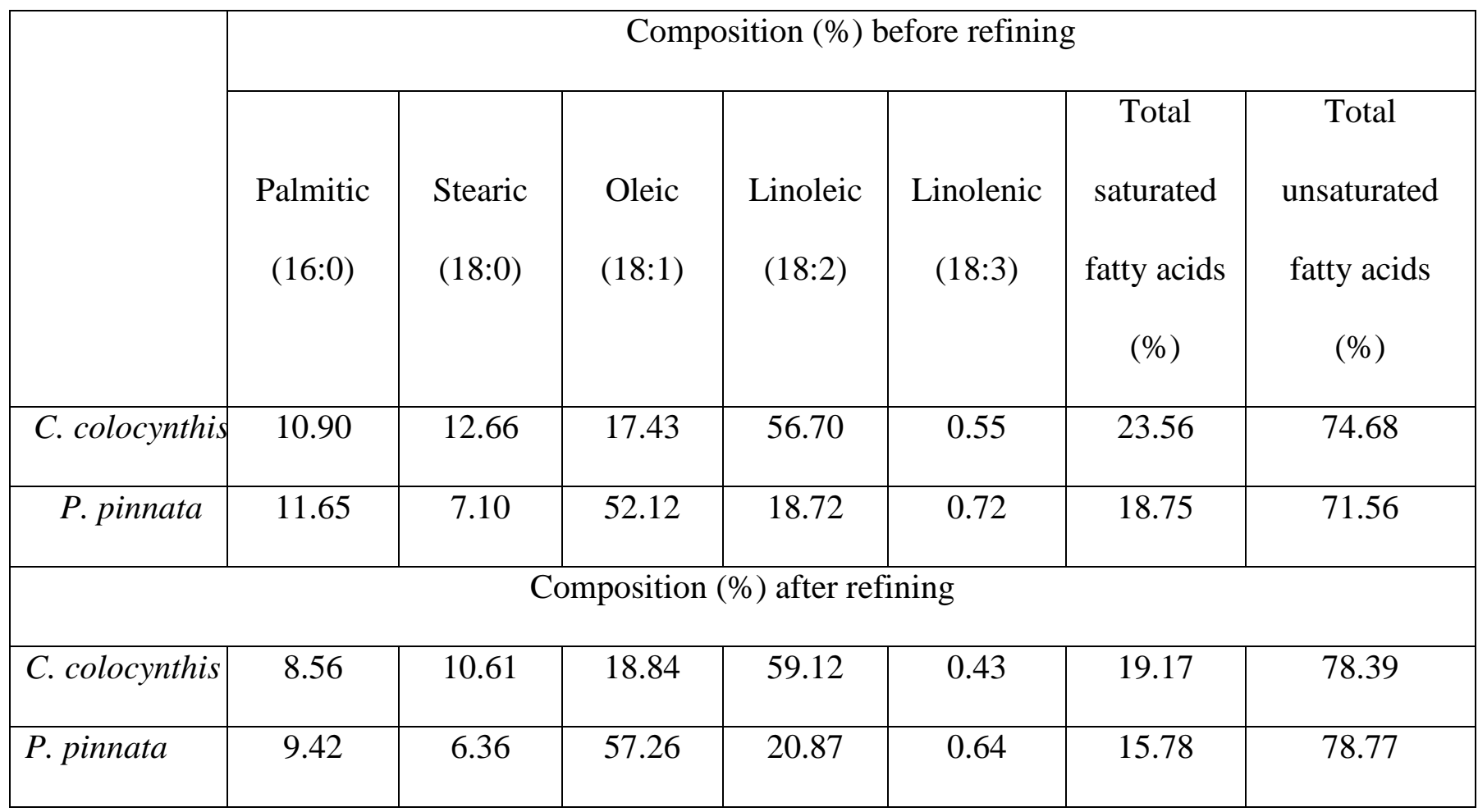

No. of replicates $(\mathrm{R})=3$ 


\section{REFERENCES}

1. Wiedermann LH Degumming of fats and oil. J. Am. Oil Chem. Soc. 1981; 53: 408-409.

2. Haraldsson G Degumming, Dewaxing and Refining. J. Am. Oil Chem. Soc. 1983; 60 (2): 251-256.

3. Demirbas A Relationships derived from physical properties of vegetable oil and biodiesel fuels. Fuel. 2008; 87: 1743-1748.

4. Ghani A Medicinal plants of Bangladesh. Asiatic society of Bangladesh, Dhaka, Bangladesh, 1998; 270 p.

5. Ziyada AK and SA Elhussien Physical and Chemical Characteristics of Citrullus lanatus Var. Colocynthoide Seed Oil. Journal of Physical Science. 2008; 19 (2): 69-75.

6. Earle FR, Glass CA, Geisenger C, Wolf A and Q Jones Search for new industrial oils. J. Am. Oil Chem. Soc. 1960; 307: 440.

7. Ahmad M, Zafar M, Khan MA and S Sultana Biodiesel from Pongamia pinnata L. Oil: A Promising Alternative Bioenergy Source. Energy Sources. 2009; 31: 1436-1442.

8. AOAC. Official methods of analysis. $14^{\text {th }}$ Edn. Association of official analytical chemists, Washington, D.C., 1984.

9. Pearson D The Chemical Analysis of Food $7^{\text {th }}$ Edition. Churchill Livingstone, London and New York.1976; 346p.

10. Rao BP, Rao SDT and BR Reddy Rapid method for determination of free fatty acid content in fatty oil. J. Am. Oil. Chem. Soc. 1972; 49: 338-339.

11. Hill SE Comparison: Measuring Oxidative stability. Inform. 1994; 5(1): 104109.

12. Luddy FE, Breadford RA, Herb SF and M Paul A rapid quantitative procedure for the preparation of methyl esters of butter, fat and other fat. $J$. Am. Oil Chem. Soc. 1968; 45: 549-552.

13. Vogel A A textbook of practical organic chemistry. $5^{\text {th }}$ edition. Longman, London. 1980; 79p.

14. Sartoretto P Kirk-Othmer Encylopedia of Chemical Technology, John Wiley Interscience, NY. 1976; 343-361 p. 
15. Erickson DR, Pryde EH, Brekke OL, Mounts TL and RA Falb In handbook of soy oil processing and utilization. American Soybean Association, $4^{\text {th }}$ edn. St. Louis, M.O. and American Oil Chemists Society, Champaign IL. 1987; 248 p.

16. Anonymous. ICAR (Indian Council for Agricultural Research), Standard Reference Handbook $16^{\text {th }}$ edition, ICAR publishing unit, 2008. pp: 122-141.

17. Bringi NV Non-traditional oilseeds and oil of India (Oxford and IBH Publication Co. Pvt. Ltd., New Delhi). 1987; 143-166 p.

18. Mabaleha MB, Mitei YC and SO Yeboah A comparative study of the properties of selected melon seed oils as potential candidates for development into commercial edible vegetable oil. J. Am. Oil Chem. Soc. 2007; 84: 31-36.

19. Duhan A, Suthar $\mathbf{Y}$, Ahlawat TR, Ahlawat KS and $\mathbf{H}$ Moudgil Refining of Psophocarpus tetragonolobus (L.DC.) Seed Oil. J. Environment and Ecology. 2009. 27 (3): 1146-1152.

20. Solomon G, Luqman $\mathbf{C A}$ and $\mathbf{N}$ Mariah Adam Investigating "Egusi" (Citrullus Colocynthis L.) Seed Oil as Potential Biodiesel Feedstock Energies 2010; 3: 607-618.

21. Duhan A, Deen MK, Dhillon RS, Ahlawat KS and TC Ahlawat Effect of Refining on Free fatty Acid and Fatty Acid Composition of Jatropha curcas L. Seed Oil. J. Environment and Ecology. 2008; 26 (2): 623-628.

22. Weiss TJ Commercial Oil Sources in Food Oils and Their Uses. West port, C.T: AVI Publishing company, Inc. 1983; 49-51 p.

23. Dijkstra AJ and VO Martin The total degumming process. J. Am. Oil Chem. Soc. 1989; 66: 1002-1009.

24. McDonnell KP, Ward SM and DJ Timoney Hot water degumming of rapeseed oil as a fuel for diesel engines. J. Agric. Engg. Res. 1995; 60(1): 714.

25. Fangrui Ma and AH Milford Biodiesel production: a review. Bioresource Technology.1999; 70: 1-15.

26. Sinram RD The added value of specialty lecithins. Oil Mill Gazetteer. September, 1991; 22-26 p.

27. Demirbas A Progress and recent trends in biodiesel fuels. Renew. Sustain. Energy Rev. 2009; 50: 14-34.

28. Sessa DJ and JJ Rakis Lipid derived flavours of legume protein products. $J$. Am. Oil Chem. Soc. 1977; 54(10): 179-181. 


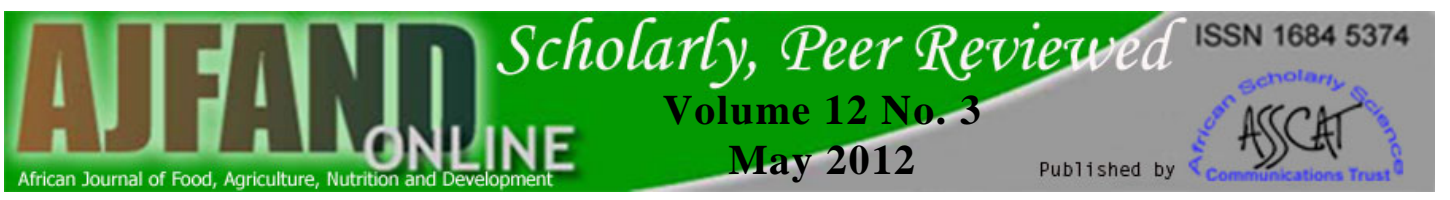

29. Rosenblum JL. Feasibility of biodiesel for rural electrification in India. Tellus Institute, Carnegie Mellon University. Draft. 2000; 1-15 p.

30. Ali A and JE McKay The chemical and physical characteristics and fatty acid composition of seed oil extracted from cruciferous species cultivated in Pakistan. J. Food Chem. 1982; 8: 225-231.

31. Ghavami $\mathbf{M}$, Gharachorloo $\mathbf{M}$ and $\mathbf{P}$ Mahasti The effect of refining operations of the qualitative properties of soybean oil. J. Agric. Sci. 2003; 9(3): 55-68. 